\title{
¿Se puede ponderar la seguridad turística? Un ensayo conceptual
}

\author{
May the tourist safety be rated? A conceptual approach.
}

\author{
Maximiliano Emanuel Korstanje (KORSTANJE, M. E.)
}

\begin{abstract}
RESUMEN - El siguiente trabajo conceptual tiene como objetivo primario revisar las dificultades en las definiciones de riesgo y seguridad para en una segunda fase arribar a la posible ponderación o presentación de un modelo que permita ponderar la seguridad turística. Desde un abordaje pragmático, es necesario incorporar diferentes variables para crear un plan integral de seguridad aplicable a la Argentina y otros países de la región. La falta de un corpus teórico en español como así también la indiferencia de los académicos latinoamericanos sobre el riesgo y la seguridad hacen necesario emprender trabajos de esta naturaleza. La tesis del presente trabajo es que la atractividad de un destino se puede explicar por la combinación de una fuerza atractiva y otra repulsiva en donde las condiciones de seguridad del viajero están en juego. Cada proceso involucra un estado liminar de incertidumbre, por medio de la cual el sujeto intenta desplegar una serie de defensas. Si el sentimiento de inseguridad es disminuido, el sujeto prosigue adentrándose en lo que no le es familiar, caso contrario, aborta el proceso o se refugia en lo que puede controlar. Se considera además que armar políticas de planificación turística acorde a encuestas y entrevistas de cómo los turistas perciben los riesgos es una estrategia incompleta e insuficiente por dos motivos. Primero y más importante, existe una dicotomía entre lo que el sujeto dice y hace. Segundo, el sujeto tiende a percibir como más seguro su propio viaje y más riesgoso el de otros.
\end{abstract}

Palabras Claves: Seguridad; Riesgo; Atractividad; Destino; Turismo.

ABSTRACT - This essay reviews is aimed at exploring not only the problems and limitation to rate the degree of security of certain destinations, but also the tourist safety at all. Following a pragmatic approach based on the needs of policy-makers and scholars in Latin America, this research provides a conceptual framework to understand the risk and its possible effects on community. The upshot for this review is that attractiveness may be explained by the combination of two contrasting forces. Each process involves a liminal state of uncertainty that may be potentiated or reduced depending on the circumstance. This would play a pivotal role in the way tourists perceive and construct the risks as well as how safe is a destination rated. First and foremost, sometimes tourists manifest a dichotomy between they say and do, for resolving these one might recur to conceptual theories in lieu of rich-empirical research. Secondly, tourists ignore why some destinations are safer than others.

Key words: Safety; Risk; Attractiveness; Destination; Tourism.

\footnotetext{
* Licenciado en Turismo, Universidad de Morón. Diplomado superior en Antropología Social y Política (FLACSO). Ph D en Psicología Social (Universidad Argentina John F. Kennedy). Profesor Investigador. Editor en Jefe de la Revista International Journal of Safety and Security in Tourism and Hospitality. Center of Business Research and Studies. Av. Dorrego 169 - 2 Piso, ap. C. CP: 1414 - Buenos Aires Argentina. Universidad de Palermo (Argentina). E-mail: maxikorstanje@ fibertel.com.ar
} 


\section{INTRODUCCIÓN}

Existe tensión entre lo que ciertos cientistas sociales consideran la seguridad y el riesgo (FABIANI y THIES, 1987; DUCLOS, 1987; TIERNEY, 1994). El sujeto puede sentirse seguro frente a determinada situación aun cuando su integridad sea amenazada como es el caso de personas quienes ante ciertos desastres naturales se niegan a abandonar su hogar, o viceversa, uno puede sentirse inseguro en forma constante cuando realmente no existe riesgo alguno, como lo es el ejemplo de los fóbicos. En los últimos años diversos modelos intentan emular condiciones sociales específicas para la percepción del riesgo con el fin de comprender y mitigar las bajas en el desempleo y los destinos turísticos, sobre todo en citaciones de extrema vulnerabilidad como ser Egipto, Bali y medio Oriente (AZIZ, 1995; ESSNER, 2005; ROBSON, 2005; PRIDEAUX, 2005; QI, GIBSON y ZHANG, 2009; NIYAZ, 2010; STEINER, 2007). Aun cuando son ilustrativos estos trabajos tienen dos fallas conceptuales importantes. La primera es que trivializan el grado de la expectativa como categoría previa a la experiencia, tema bien estudiado por S. Larsen (2007) en sus trabajos sobre la “preocupación”. Segundo, al ser un viaje un mecanismo liminar que abre y destruye la familiaridad del hogar, todo viaje supone un grado alto de incertidumbre y desconocimiento de una situación dada (LARSEN, 2007; 2009). Dependiendo de cómo se resuelve ese grado de incertidumbre el sujeto demuestra aversión o curiosidad. La percepción de riesgo como variable tiene muchos problemas para explicar además porque mientras ciertas personas evitan el peligro otros lo buscan (DOLNICAR, 2005a, 2005b). La idea central es que la seguridad turística se define por el saldo entre dos pulsiones antagónicas que se dirimen tanto de una manera positiva como negativa. En dicho proceso, el sujeto no solo evalúa las posibilidades pertinentes sino que busca, por medio de diferentes mecanismos puestos a su disposición (oferta turística), reducir el grado de incertidumbre que le genera malestar. Los diferentes grados de seguridad percibida tienen que ver con variables vinculadas a la familiaridad, compatibilidad cultural entre residentes y visitantes, idioma, receptibilidad a los medios de comunicación y disponibilidad / accesibilidad a familiares y amigos. En consecuencia, se estima que la literatura existente en turismo y hospitalidad no ha abordado el tema con claridad. Mientras el riesgo es la probabilidad propia que el sujeto asume tras su decisión, la percepción de 
seguridad es socialmente construida (LUHMANN, 1995; 1998; 2006). La percepción de seguridad se complementa por el grado de confianza que mantiene unida a una sociedad (LUHMANN, 1996); por ese motivo, es erróneo hablar de "percepción de Riesgo". Se parte de la base conceptual que el riesgo no es una categoría que puede ser percibida, ni aprehendida (KORSTANJE, 2009). En el presente trabajo de revisión no solo se cuestiona los alcances de la bibliografía clásica sobre el riesgo sino que se propone un enfoque alternativo para intentar ponderar el grado de seguridad percibida en los sistemas turísticos. Por medio de un modelo conceptual combinado de 10 variables, se intenta proveer a los investigadores un método fiable para inferir en el grado de aversión o curiosidad del sujeto para con el destino turístico.

\section{DISCUSIÓN INICIAL SOBRE EL RIESGO}

Uno de los autores que mejor ha descrito la forma moderna de concebir al riesgo ha sido el sociólogo alemán Niklas Luhmann. De sus obras, es en La Sociología del Riesgo (2006) donde mejor plantea la relación entre semiótica, confianza, poder y vulnerabilidad (LUHMANN, 1995; 1996 y 1998). Como se ha mencionado, las contribuciones de T. Parsons han sido de capital importancia para el posterior desarrollo acerca del concepto de confianza. La contingencia recíproca entre individuos y sistemas sociales es regulada por medio de medios simbólicos como la confianza y el poder, entre otros. Según Luhmann la confianza es la base de toda organización social en cuanto a que opera (en un lapso de tiempo determinado) permitiendo a los individuos reducir hasta un grado tolerable el grado de de la incertidumbre proveniente del ambiente. La confianza funcionaría como un reductor de la complejidad permitiendo que los lazos sociales puedan interactuar en un cierto grado de sincronización. "Existe solamente" dice Luhmann "un breve momento del tiempo en que me es posible ver lo que otros hacen, y adaptarme conscientemente a ello" (LUHMANN, 1996, p. 39). Si se asume que la complejidad es un factor inherente al sistema mismo, entonces se comprenderá a la comunicación y a la confianza de la misma manera. Como en Parsons, el poder, en Luhmann, se constituye como un instrumento de la comunicación, un medio simbólico cuya función es hacer inteligible las opciones entre alter y ego. En la 
vida diaria existen medios que permiten la comprensión inter-subjetiva por medio del lenguaje. La comunicación intentará, por todos los medios, resolver la contingencia (LUHMANN, 1995, p. 13).

En consecuencia con esta forma de pensar, Luhmann explica que existe una diferencia sustancial entre amenaza y riesgo. Mientras la primera se refiere a un peligro externo, en el caso de la segunda existe una decisión previa del sujeto en donde se da el principio de contingencia, eso quiere decir que el potencial daño puede ser evitado y su imprevisibilidad reducida. Por lo pronto, quienes por regla general toman las decisiones y generan los riesgos no los enfrentan. Cuando una comunidad experimenta un ataque terrorista, un accidente aéreo o un desastre natural, es común que se hable de riesgos pero ello es un concepto incorrecto. En realidad se debe hablar de amenazas ya que la víctima no tiene influencia en los efectos que causa con su decisión como así tampoco de evitar sus efectos. Lo cierto es que toda internalización de un riesgo implica la construcción de un código que se transmite gracias a la lengua. Siendo así, en Luhmann el riesgo tiene una condición sujeta a la lengua en donde se tejen alternativas decisorias con arreglo a un resultado o ganancia determinada. Por ese motivo, el conocimiento moderno genera riesgos a la vez que intenta reducirlos (LUHMANN, 2006).

Sin embargo, si se presta atención a la relación entre riesgo y decisión según ha sido planteada por Luhmann, existe una incongruencia que debe ser debatida. Es posible que el sujeto, como acertadamente explica A. Giddens, no conozca, o al menos, no tenga certeza de la totalidad de variables intervinientes a la hora de tomar una decisión. Dado el caso, el individuo debe elegir entre un rango de acciones semi-racionales, o simplemente confiar a una cadena de expertos cuyo saber absorbe el peligro en nombre del propio involucrado. Puede, incluso, decidir contratar un seguro o afrontar el peligro por su cuenta. Cualquiera sea su decisión, incluso sino decide, el sujeto está decidiendo. Por lo tanto, el error de Luhmann nace de un viejo prejuicio sistémico por el cual el hombre puede, en mayor o menor grado, acceder al total de la información que maneja el sistema. Para Giddens, la globalización y el capitalismo tardío han invadido a todas las esferas del hombre y el cálculo hoy prima por sobre todas las formas de relación posible. En consecuencia, el riesgo es un aspecto importante de la sociedad capitalista (GIDDENS, 1991; 2000). La sociedad capitalista se construye no solo alrededor del riesgo, sino además de una serie de dispositivos e instituciones como las compañías de 
seguros que mediante el pago de una cuota mensual maneja, mitiga y reduce el grado de incertidumbre para el sujeto. Al igual que Luhmann, Giddens dice que el riesgo está sujeto a un peligro que lo precede, pero no está "determinado" por la decisión del sujeto. Siguiendo este desarrollo, existirían dos tipos de riesgos, el manufacturado o creado por el sistema social mismo, y el externo, al cual los sistémicos llaman amenaza. Para Giddens, el concepto de seguridad de un grupo humano es multifacético pero opera en dos direcciones, anclado en un pasado (sociedad tradicional) o al futuro (sociedad moderna). Por ejemplo, si la sociedad tradicional medieval, con su propia idea de seguridad, se encontraba preocupada por los casos de brujería y la pérdida de la fe la sociedad industrial de hoy hace lo propio no con formas del pasado sino con el futuro. Es decir, las sociedades modernas están orientadas a manejar un alto grado de complejidad e incertidumbre producto de su propensión por el futuro. Por lo tanto, a diferencia de una aldea medieval, en la modernidad todas las acciones para mitigar un riesgo, implícitamente terminan generando otro de mayor o menor tenor (BECK, 2006; GIDDENS, 2011).

\section{LA SEGURIDAD}

En los últimos años algunos analistas han definido a la seguridad como una disposición, una especie de sensación impuesta o inducida por factores exógenos como los medios masivos de comunicación. No obstante, esa definición es infantil y errónea. La seguridad como lo hace Castel puede ser definida como una institución social anclada en la percepción pero por sobre todo en la división del trabajo y en las estructuras económicas de una sociedad. La seguridad no puede existir sin la protección. Sin ir más lejos, en la modernidad ha surgido una verdadera inflación del riesgo en donde los individuos se sienten en constante amenaza, pero paradójicamente en la edad media existían mayores peligros reales que en la actualidad. Castel explica que el grado de seguridad percibida del hombre medieval, un cuando su condición de vida era más precaria, estaba solidificado por la protección de la Iglesia Católica, pero una vez rotas las estructuras religiosas por la modernidad y la precarización del trabajo, el hombre moderno comenzó a percibir mayores peligros, no por su vulnerabilidad en sí, sino 
porque los lazos sociales se debilitan (CASTEL, 2006). Para este autor, la seguridad es imposible de ponderar en números absolutos ya que depende en gran medida de la percepción y existe una gran dicotomía entre lo que la gente dice y finalmente hace. Asimismo los diferentes ordenes económico-estructurales darían como resultados diversas maneras de vivir la seguridad. Por ejemplo, mientras en Latinoamérica se prioriza el crimen y la drogadicción como factores primarios de inseguridad, en América del norte es el terrorismo su principal flagelo. Para M. Foucault, la seguridad obedece a un mecanismo de territorialización en donde se utiliza al riesgo como una amenaza controlada de adoctrinamiento. Similar a la vacuna, la cual no es otra cosa que un virus mitigado, el riesgo permite orquestar cadenas de poder en un territorio específico que regula la escasez económica y mantiene el orden por medio de la disciplina (FOUCAULT, 2001; 2006). En Latinoamérica la seguridad, por ejemplo, está supeditada al crimen. Miguez e Isla (2010) sugieren que la seguridad es un resultado de las diferentes crisis en las estructuras sociales y económicas de un grupo. En consecuencia, todo cambio en los tejidos sociales afectan las relaciones con otros. El grado de conflictividad entre los grupos rotas las estructuras de contención es la causa del aumento de victimización en la sociedades latinoamericanas. Las diferentes transformaciones socioeconómicas sufridas por la Argentina desde el golpe de Estado de 1976 hasta la fecha, ha generado indudables falencias en los diferentes sistemas institucionales afectando al "tejido social" y la capacidad individual para poder establecer reglas claras de reciprocidad y formas de interacción. Como resultado, se pueden notar un incremento en la conflictividad social, la cual no es un tema menor puesto que no solo incrementa el delito sino la desconfianza que lleva a la victimización. La fragmentación social es la pieza clave para comprender como el miedo al delito actúa en los diferentes estratos sociales. La fragmentación crea un clima de desconfianza entre los actores sociales que conlleva la idea de una mayor distancia social. Los golpes de Estado y las diferentes políticas represivas han instalado una relación especial de desconfianza entre las instituciones y los ciudadanos. Este sentimiento de desconfianza se encuentra reforzado por los cambios y transformaciones en los cuales el Estado se ha mantenido ausente. La combinación de ambos factores hace que la victimización sea mayor en aquellos sectores que no solo no se encuentran contenidos sino que se perciben como distantes del poder estatal. El aumento de la 
percepción de inseguridad es proporcional a la fragmentación durkheimiana del lazo social (MIGUEZ y ISLA, 2010). Por el contrario, G. Kessler afirma que la seguridad o su carencia se corresponden con un dispositivo de exclusión y dominación de ciertos grupos sobre otros. Siempre anclada a un territorio ajeno, la inseguridad es construida socialmente como un mecanismo que confiere estabilidad al orden político e identidad a quienes forman parte del grupo (KESSLER, 2009).

\section{INCERTIDUMBRE ANTE EL VIAJE}

Todo hombre teme a la muerte, y en el viaje a la posibilidad de encontrarla. El sistema de transporte turístico se concibe en base a tres elementos, un centro emisor de personas, un canal liminar por el cual se lleva a cabo cierto desplazamiento por medio de tecnologías específicas y un centro receptor en donde el viajero arriba emulando el confort del propio hogar (CALLIZO-SONEIRO, 1991, p. 18). Si bien no existe consenso sobre cual de los tres componente genera un grado de atractividad mayor en la afluencia turística, lo cierto parece ser que desde el momento en que una persona se ausenta fuera de su hogar por motivos de descanso, profesión, negocios y otros por más de 24 horas y menos de 6 meses, se está en presencia de un viaje que puede muy bien denominarse turístico. Estos desplazamientos no son casuales y se encuentran insertos en un sistema que no solo los contiene sino que define las diferentes funcionalidades de los actores. Algunos especialistas prefieren hablar de sistema turístico y no de turismo. Según el modelo de Molina, el sistema turístico se compone de: En primer lugar, a) una superestructura, formada por leyes, normas y reglamentos, b) una demanda, representada por los turistas c) infraestructura, cuya función es dar soporte y permitir la comunicación entre las partes, como por ejemplo puede ser carreteras, aeropuertos etc., d) atractivos, que los clasifica como naturales o culturales e) equipamiento, vinculado a hoteles, agencias de viaje y otras empresas f) una comunidad o grupo receptor, que hace referencia a los residentes del lugar (MOLINA, 1986).

Se parte de un centro emisor camino a un receptor imaginando ciertos riesgos pero nadie imagina encontrar a la muerte en dicho proceso. Como afirma Sartre el hombre que en su libertad de elección se ve comprometido con su propia existencia se 
encuentra vinculado a un sentimiento de angustia. Asimismo, ella no es propia inacción sino que surge de la responsabilidad por la decisión que se ha adoptado. Un jefe militar si toma la responsabilidad de atacar tiene a su cargo una cantidad de soldados de quienes depende su vida; de la interpretación de una persona que ejerce la jefatura surge la angustia ya que enfrentan una pluralidad de alternativas pero sólo una puede tomar (SARTRE, 1997, p. 18). Para Elías y Dunning la vida cotidiana es tan impersonal y racional que los hombres deben circunscribir sus emociones a espacios determinados como los espectáculos deportivos y los viajes. Los viajes tienen la particularidad de mantener un grado de tensión en el sujeto (regulado) cuyo destino es darle placer una vez que llega sano y salvo a destino. El hombre moderno inserto en la cotidianeidad alienante de las grandes ciudades busca espacios de emoción y tensión para poder equilibrar su psiquis. El temor imaginado por los turistas durante su viaje se diluye cuando éstos encuentran toda una serie de dispositivos de seguridad a su disposición. En consecuencia, para los autores viajar no sólo que se constituye como una actividad de cierta forma segura sino agradable y deseable (ELIAS y DUNNING, 1992). La angustia surge de la incertidumbre cuando el sujeto se enfrenta a la nada. Si se comprende al "ser" como el cuestionamiento propio del "ente", en carácter de tal el ser debe preguntarse y buscarse así mismo. La angustia debe ser comprendida como un estado de doble carácter. Por un lado, sigue una dinámica ascendente por el otro descendente. Si la nada no puede eliminar al ser-ahí y éste decide seguir existiendo, entonces nace la angustia. Mientras la angustia está condicionada por lo futuro - que aún no es - y se manifiesta en el ser hacía-fuera, el miedo surge del accionar específico de los otros en uno mismo, hacia-dentro. En este sentido, Heidegger (1996, p. 47) aclara que mientras el miedo se funda a sí mismo en un objeto determinado (miedo-a o miedo-de) por estímulo directo externo sobre el Dasein, la angustia se caracteriza por una constante indeterminación (angustia-por) hacia fuera. En otras palabras la angustia misma no vacía el sentido es la falta total de sentido frente a la libertad humana. La contingencia y la ambigüedad son dos condicionantes de la angustia. S. Plog estudio la predisposición del sujeto a los viajes acorde a un modelo multivariable de relaciones. ¿Por qué ciertas personas desarrollan riesgos a ciertos objetos y no otras?, ¿Por qué ciertos riesgos son percibidos como mayormente peligrosos respecto a otros? Plog argumenta, en principio convincentemente, que la personalidad es un criterio importante para condicionar la 
elección de un destino turístico. Si bien fue muy criticado por falta de rigurosidad experimental, Plog dice que existen tres tipos de viajeros (alocéntricos, mid-céntricos y psico-céntricos) acorde al tipo de reacción que demuestran ante un escenario desconocido. Por medio de un continuum los tipos alocéntricos buscan variedad y aventura, son seguros de sí mismos y no necesitan de viajes organizados; por el contrario, los psicocéntricos se mueven acorde a normas establecidas, son en ocasiones miedosos o nerviosos y necesitan de un viaje organizado. En trabajos posteriores Plog (1991) enumera 28 características que son extraídas de tres rasgos dominantes en la personalidad, a) la limitación del territorio, b) la ansiedad y c) el sentido de la impotencia. A estas dimensiones les agrega la energética/no energética como categorías anexas. El objetivo de Plog (cuyo proyecto fue financiado por compañías aéreas) llevaba como objetivo demostrar que aquellos con un alto poder adquisitivo que no deseaban volar (non-flyers) en sus viajes desarrollaban una personalidad de tipo fóbica con un alto tradicionalismo, y dependencia con "fuertes vinculaciones territoriales" a los cuales encasilla dentro del tipo psico-céntrico (PLOG, 1973; PLOG, 1991). La disposición del ego respecto al peligro y las diversas reacciones para enfrentarlo o evitarlo, es sin lugar a dudas, una de las contribuciones de Plog al estudio psicológico del riesgo. Su legado ha sido retomado por otros investigadores como Reisinger y Mavondo (2003) quienes demostraron que la ansiedad repercute no solo sobre la personalidad sino sobre las intenciones de viaje. Si se parte de la base que la cultura, la historia y las experiencias previas condicionan el lugar en el mundo de un sujeto, entonces se asume que los eventos son clasificados dependiendo de estructuras cognitivas previas. El grado de aversión o atracción respecto a un sitio donde se llevaron a cabo matanzas generalizadas dependería de la personalidad del visitante y no de factores externos. Por lo tanto, la personalidad selecciona y re-encuadra ciertos sucesos como riesgosos despertando mayores o menores grados de ansiedad. Pero en este proceso, el sujeto cumple un rol proactivo. De esta forma, es posible afirmar que los límites nacionales actúan como barreras profilácticas respecto al riesgo, pero sólo en ciertas personalidades (REISINGER y MAVONDO, 2005).

En perspectiva, se puede afirmar que el viaje es un factor de ansiedad y angustia en el sujeto. La posibilidad de no ser bien recibido es una de las cuestiones más angustiantes en los viajes, incluso los turísticos. Por ese motivo, una vez imaginado el 
viaje turístico se ponen en funcionamiento una serie de mecanismos anclados en la fantasía que operan con mayor o menor atractividad en la mente del consumidor. El turismo se origina en dos necesidades contrastantes pero igualmente fuertes, la curiosidad por explorar lugares nuevos y la necesidad de un ambiente conocido y estable. Cuando el grado de incertidumbre sobrepasa a las barreras propias de la sociedad el viajero retorna a su hogar mientras que decide permanecer cuando la curiosidad es mayor a la protección. Los autores consideran que existen dos tendencias una turística que busca lo nuevo, y la otra nativista que permite el turista regrese a casa (GEORGE, INBAKARAN y POYYAMOLI, 2010). Por ese motivo, a continuación se examinarán las diferentes variables que entran en juego para conformar la seguridad turística percibida. En forma pragmática, la seguridad turística integral ha sido históricamente de gran importancia para medir, cuidar y ampliar la atractividad de un destino.

En este sentido, P. Tarlow (2011) afirma que la seguridad turística depende de la eficiencia del sistema para mitigar los peligros del ambiente diferenciando claramente concepto tales como manejo del riesgo (risk-management) de manejo de desastres (disaster management) o manejo de crisis (crisis-management). La perspectiva científica ha desarrollado demasiadas definiciones sobre los desastres, las crisis y los riesgos, pero para los analistas de la industria es menos importante las definiciones de que se entiende por riesgo cuando lo que está en juego es el buen funcionamiento de la actividad y los impactos económicos o políticos que implica cualquier crisis. Industrias complejas si las hay, el turismo ha generado un sinnúmero de efectos positivos en el mundo globalizado que van desde la educación hasta la generación de empleo. No obstante su sensibilidad a eventos de naturaleza conflictiva atentan directamente contra el bienestar y la distribución de la renta en los países industriales y en los emergentes. Planificar, mitigar y neutralizar los riesgos contra los destinos turísticos es un objetivo a largo plazo entre las organizaciones mundiales y las naciones. Para ello, es necesario hacer una correcta clasificación entre lo que es una catástrofe, una crisis o un riesgo. Para el autor, el manejo de crisis sólo es posible cuando la planificación para controlar al riesgo falla. Si el riesgo no es debidamente identificado y corregido, el orden social puede enfrentar un desastre, lo cual a su vez puede generar un estado extendido de crisis (TARLOW, 2011). No obstante, como lo evidencia L. Pennington-Gray et al existen condiciones en 
donde el ser humano es quien genera el riesgo como ser el caso de la Bahía de México y el desastre natural del derrame petrolero. En ocasiones una crisis despierta e involucra a ciertos actores que se apartan de todo plan pre-establecido y actúan con espontaneidad y responsabilidad. De estos eventos, se aprenden lecciones que llevan a re-hacer un nuevo plan de contingencia en momentos de crisis (PENNINGTON-GRAY et al., 2011).

Por su parte, S. Buus afirma que el mundo globalizado y la audiencia es testigo de cómo en las últimas décadas han aflorado una serie de miedos que antes se encontraban al menos, escondidos. Desde atentados terroristas, hasta desastres naturales o riesgos microscópicos como intoxicaciones o brotes de nuevos virus, el mundo se encuentra determinado por la catástrofe. Siguiendo este argumento, es necesario homogeneizar la legislación vigente con el fin de crear un código único de seguridad aplicable a todos los países del mundo. La legitimidad y poder de los estados nacionales, advierte Buus, no están en declive sino que se han retraído dejando al mundo en una especie de inseguridad crónica. Para corregir la falla, que ha nacido con la modernidad, los estados deben someterse a una única ley (llamada consular cathastrophe law) que abogue por la seguridad de todos (BUUS, 2011). En perspectiva, Larsen et al (2011) demuestran que los turistas conciben al riesgo como algo lejano que sólo puede sucederles a otros y no a ellos mismos. Existe, entonces, una dicotomía conceptual respecto a la percepción por la cual el hogar es construido como más seguro que el afuera, aunque los peligros reales fueran inversamente proporcionales. Este hallazgo para los autores no es sensible a las diferencias culturales y nacionalidades. Sin importar la edad, nacionalidad y profesión un gran porcentaje de turistas consultados dijo sentirse más seguro en el hogar que mientras estaba de viaje. A su vez, una mayor proporción también identificó una gran cantidad de riesgos en viajes de otras personas.

\section{PROBLEMA CONCEPTUAL DE LAS ESCALAS DE RIESGOS}

En la sección anterior se ha señalado que el riesgo puede ser concebido como una probabilidad de daño, y ha sido esta concepción la que ha impulsado a los investigadores a pensar que los índices de co-variación de variables pueden ayudar a comprender y leer mejor como se construye el riesgo. Estas encuestas, particularmente, 
son conducidas por estudiantes que tienen poca o escasa experiencia en el tema en lugares como aeropuertos o terminales no aptos para su aplicación. Momentos antes de partir a un viaje, las posibles ponderaciones del encuestado están marcadas por un alto grado de incertidumbre y por lo tanto son tendenciosas. Además, algunas escalas persiguen intereses políticos e ideológicos que llevan implícitamente al etnocentrismo (KORSTANJE, 2010). Segundo, las encuestas - por ser radiografías del momento - son incapaces de detectar la construcción subjetiva de los riesgos ya que su naturaleza es situacional. Una misma persona puede en determinado día concebir mayores o menores riesgos, o incluso diferentes dependiendo de sus expectativas. Tercero, la correlación estadística implica un nexo causal entre dos variables pero no responde a la causalidad entre esas dos variables. Por ejemplo, se puede ver dos casos que son paradigmáticos y ayudarán al lector a comprender el problema del riesgo. Una encuesta en una población estadísticamente representativa asume que las mujeres perciben mayor riesgo a volar en avión que los hombres. Según una lectura de segundo orden, la cual caracteriza a la teoría actualmente, las mujeres son más propensas al riesgo que los hombres. Sin embargo, dicha afirmación es completamente superficial. Las mujeres no perciben mayores riesgos por su calidad o estatus sino por haber sido socializadas bajo valores culturales específicos que presuponen que la mujer debe expresar sus sentimientos mientras el hombre debe reprimirlos. En ese contexto, ello no sugiere que el hombre tema menos que la mujer sino que: disfraza ese temor en ira, o lo reconoce internamente pero lo oculta externamente. En este caso la extensividad y rugorisidad muestrearía no puede responder por la causa del fenómeno. Un segundo ejemplo puede ser también ilustrativo. La estadística demuestra que las mujeres chocan un 50\% más que los hombres. Una lectura de segundo orden releva que ello puede deberse a que no manejan tan bien como los hombres, no obstante un abordaje más profundo sugiere que las mujeres están más agobiadas que los hombres y que esa es la causa del mal manejo. En resumen, los ejemplos dados ayudan a distinguir como las estrategias cuantitativas pueden presentar un panorama de la situación pero no es sino por medio de una perspectiva cualitativa o una combinación entre ambas que se puede profundizar en las razones de lo que se observa (ZINN, 2010). 


\section{VARIABLES INTERVINIENTES EN LA SEGURIDAD TURISTICA}

La seguridad turística es un aspecto vital en la organización de los destinos. El debate se encuentra marcado por la idea, sostenida por algunos, que la seguridad no es un objeto que pueda ser operacionalizado en variables; por el contrario, para otros en donde se inserta nuestra postura, existen variables claras que permiten ponderar ciertos umbrales por medio de los cuales la toma de decisiones del turista se hace efectiva. $\mathrm{Si}$ las condiciones de seguridad, producto de la falta de control de la incertidumbre, no son óptimas, el sujeto tenderá a recluirse o a evitar el destino. Por ese motivo, es necesario proveer un marco conceptual que permita examinar la relación que tiene la información y la percepción en la construcción de lo que es un destino seguro. Tomamos en cuenta los factores técnico, de visado o migratorio, información y compatibilidades culturales como estructuras de análisis más significativas.

\subsection{NIVEL DE INFORMACIÓN DISPONIBLE SOBRE EL DESTINO}

El nivel de información disponible (y la facilidad con la que se accede a ella) en la sociedad de origen sobre determinado destino es crucial a la hora de organizar un viaje. Sobre la variable Nivel de información disponible existen dos valoraciones posibles, positiva la cual da como resultado una reacción de interés por el destino. En este caso, el viajero encuentra copiosos datos sobre el lugar que le permiten imaginar un lugar ideal. Ese paraíso ideal lo ayuda a resolver su disonancia cognitiva, es decir el grado de ansiedad surgido por no conocer previamente el destino. Por el contrario, si dicha información no estuviera debidamente al alcance del interesado, la reacción sería la indiferencia. Ahora bien, el grado de información disponible no es suficiente para predecir la propensión o aversión de un consumidor por un destino. Por ejemplo, durante muchos años la imagen de Irlanda del Norte ha sido mala, debido a la sobrecarga informativa, películas y libros sobre el terrorismo de I. R. A., aun siendo un lugar de hermosos paisajes. En este caso, la información está disponible a cualquiera que quiera visitar Irlanda del Norte, pero la categorización de este destino es negativa. 


\subsection{REQUERIMIENTOS DE VACUNAS}

Otro elemento importante para la seguridad percibida del turista es la cantidad de enfermedades y virus que potencialmente pueden ser desagradables o mortales para el viajero como así también la cantidad de vacunas disponibles que ayudarán a reducir la incertidumbre. Aquellos destinos con enfermedades para las cuales no existe vacuna, su grado de atractividad tenderá a ser menor en comparación a aquellos donde no existen enfermedades. Sin embargo, aun cuando existan enfermedades que pueden ser mitigadas por ciertas vacunas el grado de seguridad percibida se mantendrá estable y el destino no perdería atractividad. En resumen, la incertidumbre de un viajero con respecto a un virus o bacteria es realmente alta por dos motivos, el primero y más importante, el virus es invisible al ojo humano y segundo, por tanto escapa a su control. Una de las características más angustiantes de los virus es que no pueden ser controlados por la visión, mucho menos visualizados con claridad a diferencia de otros riesgos. Los virus desafían el valor conferido por Occidente del control ocular.

\subsection{REQUERIMIENTOS DE VISADO}

Además de las vacunas y la información, un aspecto principal que posibilita el turismo es el grado de hospitalidad de un estado y los requerimientos burocráticoformales que se le pide a los extranjeros para viajar y permanecer en un territorio. Aquellos destinos con mayores requerimientos de visado tendrán menor atractividad que aquellos con menores formulaciones. Ello se debe a un principio psicológico básico anclado en la "deseabilidad" de ser bien recibido. Una de las cuestiones más angustiantes antes de realizar un viaje al extranjero es ser rechazado por el país anfitrión. El principio de hospitalidad tiene una gran fuerza en la relación entre las naciones y el flujo de sus pasajeros. La visa es una norma (estatutaria) entre países de permiso y tránsito de personas. Su tipología puede ser variada, y encierra una acabada noción de reciprocidad entre aquellos estados que celebran el convenio. Precisamente, es sobre la significación política de hospitalidad que se fundamenta la solidaridad entre los grupos. La hospitalidad se asienta sobre la base de un sistema (legal-racional) de visado. Como precondición el estado anfitrión debe conocer el patrimonio e identidad 
del solicitante. La recepción o rechazo del extranjero corresponde a ciertas prácticas que marcan la forma económica de la sociedad. Sociedades nómadas y pobres tenderán a ser más hospitalarias que las ricas y sedentarias.

\subsection{PROBLEMAS EN LOS VUELOS}

En la industria turística la demora de vuelos o robo de equipajes es algo común. Para el caso de los segundo existen diversos seguros a contratar, para el primero no. Las diferentes luchas gremiales entre y legislación laboral muchas veces deja a los turistas varados en los Aeropuertos durante días sin posibilidad de reconducción hacia sus respectivos destinos. En este sentido, el grado de incertidumbre es tan alto que genera dos reacciones bien diferentes, indiferencia/ interés en el caso de ser un país con alta o baja conflictividad laboral respectivamente.

\subsection{NOTICIAS LOCALES NEGATIVAS SOBRE COYUNTURA ECONÓMICA Y DISCREPANCIA CULTURAL}

Un viajero comienza su travesía en su imaginación ya sea en la lectura de alguna novela o por las reminiscencias de alguna experiencia que viene desde la niñez. La fantasía juega un rol fundamental en este proceso pero no es la única variable. Los medios masivos de comunicación, en tanto que reforzadores morales de una sociedad, advierten sobre potenciales problemas en ciertos destinos generando mayor o menor atractividad dependiendo el grado de seguridad percibida del viajero. Dos reacciones son, contextualmente, posibles dados el flujo informativo sobre la audiencia, aversión en caso de experimentar un desmedido nivel de incertidumbre y atracción en caso de experimentar un nivel controlado de seguridad.

\subsection{COMPATIBILIDAD DEL IDIOMA}

Todo lenguaje configura la esencia y su estar en el mundo de cualquier comunidad. El lenguaje es un aspecto fundamental de la vida social de los hombres. En efecto, la construcción simbólica del mundo se encuentra ligada a las estructuras 
lingüísticas. Por ende, no existe cultura fuera del lenguaje. Los pensamientos son tan inseparables de la lengua como ésta misma lo es de los pensamientos. El nivel de seguridad y familiaridad previo que fundamenta el consumo turístico se explica por la posibilidad de poder expresarse y ser entendido por otros. Cuando eso no sucede, el viajero se siente más vulnerable e inseguro. Ante un potencial incidente, el viajero se encuentra imposibilitado de expresarse con claridad en busca de ayuda.

\subsection{ACCESIBILIDAD A CADENAS DE AMIGOS}

Muchos autores han demostrado que viajar con amigos reduce la percepción de riesgos. Los familiares denotan un vínculo social cuya necesidad de pertenencia permiten la reducción de peligros percibidos ya que al disminuir el grado de incertidumbre, aumenta la seguridad percibida. Empero, si las variables anteriores no están controladas, el grado de inseguridad - aun cuando el sujeto viaje con un núcleo familiar - sigue siendo alto. Es decir, los familiares confieren mayor seguridad a la hora de viajar debido a que crean un lazo de confianza cuando el destino es visitado por vez primera. Ello sucede siempre y cuando no primen noticias de eventos negativos que pueden atentar con sus familiares, haya compatibilidad de idioma e información y soporte suficiente en caso de sufrir algún inconveniente. El temor no solo se fundamenta sobre uno (self) sino sobre otros. Si las variables que hacen a la seguridad turística, según el presente modelo, no están controladas entonces la seguridad turística percibida ser deficiente y la atractividad del destino negativa.

\subsection{EXPERIENCIA PREVIA}

La experiencia previa como variable no significa por sí que el viajero sea inducido a cierto destino y descarte otro que no conoce por una simple razón. Muchas veces el sujeto es conducido a consumir lo que ya conoce, y se evade de lo que no les familiar, pero en otros contextos, la reacción es diferente. De todos modos, la experiencia previa como variable permite inferir hasta que punto el sujeto, dependiendo de su estructura psicológica, se siente más o menos seguro. 


\subsection{SEGURIDAD INTEGRAL}

El concepto de seguridad integral se encuentra vinculado a la potencial percepción y o expectativa de sufrir un daño u evento que puede afectar seriamente la integridad física del viajero o su núcleo de viaje. Dependiendo de la carga y la valorización, las reacciones ante situaciones de stress como ser un robo, crimen o atentado, van desde el temor propiamente dicho hasta la curiosidad. En este punto la experiencia previa del destino y la accesibilidad de amigos para hacer frente a la situación serán muy importantes. Mientras la curiosidad abre al self a nuevas experiencias, el miedo lo cierra y lo pone en una situación evitativa. Existen ocasiones incluso donde, si el self no pueden mantener el grado de incertidumbre, recurre al consumo de psico-fármacos, drogas y alcohol. Los estudios hechos en mochileros (REICHEL, FUCHS y URIELY, 2007) demuestran que el consumo de sustancias reduce la percepción de riesgos negativos, no obstante metodológicamente no existe claridad acerca de si es el rol aquel que fundamenta la actitud o el consumo de sustancias que nublan el juicio. Por ejemplo, el grado de seguridad percibida bajo consumo de alcohol puede ser mayor en ciertas circunstancias, y caer a grados insospechados cuando se van los efectos del mismo. En resumen, el rol del viajero no es una variable suficiente para comprender como se organiza el sentimiento de seguridad y el riesgo real.

VARIABLES INTERVINIENTES EN LA SEGURIDAD TURISTICA

\begin{tabular}{lll}
\hline Tabla de variables a la seguridad turística. & \multicolumn{2}{l}{ Valoración positiva / Negativa } \\
\hline Nivel de Información Disponible sobre el destino & Interés & Indiferencia \\
Requerimientos de vacunas & Retracción & Expansión. \\
Requerimientos de visado & Retracción & Expansión \\
Problemas en los vuelos. & Indiferencia & Interés \\
Noticias locales negativas sobre coyuntura económica & Aversión & Atracción \\
Discrepancia cultural con el consumo & Aversión & Atracción \\
Compatibilidad de Idioma & Socio-centrismo & Etnocentrismo
\end{tabular}


Continuação...

Accesibilidad a cadenas de familiares y amigos

Seguridad

Inseguridad

Experiencia previa con el destino

Seguridad

Inseguridad

Seguridad integral sobre el turista en el destino

FUENTE: ELABORACIÓN PROPIA.

Curiosidad Miedo

Dependiendo del tipo de variable interviniente en el armado del plan de seguridad, se asumen dos tipos de valencias, positiva y negativa. Ante una valorización positiva la reacción del turista será diferente en comparación a una negativa. Cuando el nivel de información es escaso, por ejemplo, el turista demuestra indiferencia, asimismo si el destino manifiesta información suficiente pero pide muchos requisitos respecto a la vacunación o visado, la respuesta será "la retracción” o aversión a ese destino. También las situaciones de vuelos representan respuestas que pueden afectar seriamente al destino. Aunque las variables precedentes despierten una reacción positiva, si la conectividad con el destino es mala o existe problemas en los vuelos, el turista tenderá a utilizar otras formas de transportes. Por último pero no por eso menos importante, la compatibilidad del idioma y la experiencia previa del destino juegan roles importantes a la hora de percibir un destino como seguro o inseguro. La tendencia a abrirse o cerrarse ante un medio nuevo que no es familiar. El resultado final será una actitud proactiva de descubrimiento y exploración propia de la curiosidad, o un rechazo manifiesto por temor. Las variables representan, en este cuadro, situaciones que el turista enfrenta antes y durante su viaje como así también sus diversas reacciones. Dependiendo de cómo se resuelven cada una de las situaciones, la ponderación total será positiva (atracción), o negativa (aversión). En ocasiones, el orden puede no darse como se ha explicado en el cuadro, no obstante cada una de ellas tiene un gran impacto en la decisión final. Los abordajes empíricos no pueden revelar este esquema teórico debido a dos circunstancias importantes. Muchas veces el entrevistado no conoce el motivo de su comportamiento, segundo existe una dicotomía entre lo que la gente dice y hace. Para resolver esa cuestión, abordajes conceptuales holístico se tornan necesarios. Si bien el presente trabajo no resuelve todas las cuestiones que hace a la seguridad turística, pone el foco en sus variables más importantes con el fin de poder ampliar al actual entendimiento del problema. 


\section{CONCLUSIONES}

Las dificultades para definir y comprender al riesgo vienen a menudo asociadas a políticas que no logran proteger al turista en forma eficiente. La primera gran clasificación que se puede hacer sobre los riesgos son aquellos generados por el sistema turístico y aquellos que le son externos. Se dan, por lo tanto, riesgos turísticos y riesgo extra-turísticos. Dentro del primer sub-tipo se puede subdividir en riesgos "asociados al servicio", que van desde la perdida de un avión, el equipaje hasta la derivación a otro hotel por sobre-ocupación o una huelga; y asociados a "la seguridad personal del turista". Los del segundo subtipo son peligros que afectan directamente y físicamente la seguridad del turista durante su estadía. Los riesgos sobre el servicio afectan a menudo a un conjunto de compañías pero no involucra al destino como un todo orgánico, en cambio los riesgos asociados a la seguridad (cuando toman un estado público masivo) pueden generar una imagen negativa que afecta a toda la ciudad. Por ejemplo, cuando un turista que arriba a la ciudad de Nueva York pierde su vuelo o su estadía producto de una huelga repentina, su imagen sobre el destino sigue siendo positiva. Cuando se trata de un evento que tiene una gran carga afectiva como ser un atentado o una guerra civil, la atractividad del destino (por el contrario) queda seriamente afectada. Para ello es importante comprender y definir los límites de la seguridad turística como así también su rango de operatividad. No obstante, la seguridad turística continúa siendo un campo poco estudiado en Argentina y Latinoamérica en general, aun cuando se cuenta con diversos estudios en Europa y América del Norte. Si bien la noción de seguridad es socialmente construida y por tanto no puede ser ponderada por medio de una encuesta 0 entrevista, existen indicadores que permiten una mayor comprensión del fenómeno. Dichos indicadores conforman lo que en este trabajo se han denominado "seguridad percibida integral" y condicionan el grado de aversión o propensión del sujeto a determinados destinos. Como afirma Tarlow (2011), y dejando la ortodoxia científica de lado, es necesario establecer modelos pragmáticos que permitan el buen funcionamiento de la industria. En este sentido, el nivel de información, la accesibilidad a redes de familiares y amigos, la acción del periodismo y los medios de comunicación entre otros son aspectos esenciales a tener en cuenta en cualquier plan de evaluación para mejorar la seguridad de un destino. 


\section{REFERENCIAS}

AZIZ, H. Understanding attacks on tourists in Egypt. Tourist Management, 16, 1995, pp. 91-95.

BECK, U. La Sociedad del Riesgo: la sociedad del Riesgo. Buenos Aires, Paidós, 2006.

BUUS, S. (2011). The People's Home goes Gulliver: Sweden and the 2004 Tsunami Crisis. Int. Journal of Tourism Anthropology. Special issue on Narrives of Risk, security \& Disasters issues in Tourism and Hosp. Korstanje, M. (editor). Vol. 1 (3-4), pp. 293303.

CASTEL, R. La Inseguridad social: ¿Qué es estar protegido?. Buenos Aires, El Manantial, 2006.

CALLIZO-SONEIRO, J. Aproximación a la Geografía del turismo. Madrid: Editorial Síntesis, 1991.

DOLNICAR, S. Fear Segment in tourism. CD Proceedings of the 14 International Research Conference of the Council for Australian University and Hospitality Education. CAUTHE. 1-5 Febrero de 2005, Australia, 2005a.

DOLNICAR, S. Understanding barriers to leisure travel, tourists fears as marketing basis. Journal of Vacation Marketing, 11 (3), 2005b, pp. 197-208.

DUCLOS, D. Le Risque: une construction sociale?. En J. Fabiani, y J Thyes. La Societeé Vulnerable. Paris, Ecole Normale Superieure, pp. 91-92, 1987.

ELIAS, N.; DUNNING, E. Deporte y Ocio en el Proceso de la Civilización. Buenos Aires: Fondo de Cultura Económica, 1992.

ESSNER, J. Terrorism's impact in Tourism: what the industry may learn from Egypt's struggle with al-Gama'a al-Islamiya. Security and Development. IPS 688, 2005.

FABIANI, J. L.; THYES, J. La Societeé Vulnerable. Paris, Ecole Normale Superieure, 1987

FOUCAULT, M. Defender la Sociedad. Buenos Aires, Fondo de Cultura Económica, 2001.

FOUCAUlT, M. Seguridad, Territorio, Población. Buenos Aires, Fondo de Cultura Económica, 2006. 
GEORGE, B.; INBAKARAN, R.; POYYAMOLI, G. To Travel or Not to travel: towards understanding the theory of nativistic motivation. Tourism, an international interdisciplinary Journal. Vol. 58 (4), 2010, pp. 395-407.

GIDDENS, A. Modernity and Self-Identity: Self and Society in the Late Modern Age. California, Stanford University Press, 1991

GIDDENS, A. Un Mundo desbocado. Los efectos de la globalización en nuestras vidas. Madrid, Taurus, 2000.

GIDDENS, A. The Politics of Climate Change. Cambridge, Polity Press, 2011.

HEIDEGGER, M. ¿Qué Es la metafísica?. Buenos Aires: Ediciones Fausto, 1996.

HEIDEGGER, M. El Ser y el Tiempo. Santiago: Editorial Universitaria, 1997.

KESSLER, G. El Sentimiento de Inseguridad: sociología del temor al delito. Buenos Aires, Siglo XXI, 2009.

KORSTANJE, M. Re-visiting the risk perception theory in the contexts of travels. ERTR: e-review of Tourism Research. Vol. 7 (4), 2009, pp. 68-81.

KORSTANJE, M. El 11 de Septiembre y la teoría de la Percepción del Riesgo. Pasos: revista de turismo y patrimonio cultural. Vol. 8 (2) 2010, pp. 389-402.

LARSEN, S. Aspects of a Psychology of the Tourist Experience. Scandinavian Journal of Hospitality and Tourism. Vol. 7 (1), 2007, pp. 7-18.

LARSEN, S. What Tourists worry about: construction of a scale measuring tourist worries. Tourism Management. Vol. 30, 2009, pp. 260-265.

LARSEN, S.; NING, Z.; WANG, J; OGAARD, T; LI, X; BRUN, W. (2011). Are East Asian Tourists more apprehensive about food risks?. Int. Journal of Tourism Anthropology. Special issue on Narrives of Risk, security \& Disasters issues in Tourism and Hosp. KORSTANJE, M. (editor). Vol. 1 (3-4), pp. 226-238.

LUHMANN, N. Poder. México, Universidad Iberoamericana, 1995.

LUHMANN, N. Confianza. México, Editorial Anthropos, 1996.

LUHMANN, N. Sistemas Sociales. Lineamientos para una teoría General. Barcelona, Anthropos, 1998.

LUHMANN, N. Sociología del Riesgo. México, Universidad Iberoamericana, 2006. 
MIGUEZ, D.; ISLA, A. Entre la Inseguridad y el Temor. Instantáneas de la Sociedad Actual. Buenos Aires, Paidos. 2010.

MOLINA, S. Planificación del Turismo. México: Nuevo tiempo Libre, 1986.

NIYAZ, A. Terrorism and Extremism: a threat to Maldives Tourism Industry. Unisci. Discussion Papers. N. 24, 2010. Octubre.

PENNINGTON-GRAY, L.; LONDON, B.; CAHYANTO, I; KLAGES, W. (2011). Expanding the Tourism Crisis management planning Framework to include social media; lessons from the Deepwater Horizon Oil spill 2010. Int. Journal of Tourism Anthropology. Special issue on Narrives of Risk, security \& Disasters issues in Tourism and Hosp. KORSTANJE, M. (editor).Vol. 1 (3-4), pp. 239-253.

PLOG, S. "Why destination areas rise and fall in popularity". The Cornell Hotel and Restaurant Administration Quarterly, 13 (3), 1973, pp. 13-16.

PLOG, S. Leisure Travel; making it a growth market again!. Nueva York, Ed. Wiley and Sons, 1991.

PRIDEAUX, B. Factors affecting bilateral tourism Flows. Annals of Tourism Research. Vol. 32 (3), 2005, pp. 780-801.

QI, X. C.; GIBSON, H.; ZHANG, J. Perception of risk and Travel Destinations. The case of China and the Beijing Olympic Games. Journal of Sports \& Tourism. Vol. 14 (1), 2009, pp. 43-67.

REICHEL, A.; FUCHS, G.; URIELY, N. Perceived Risk and the non-instituonalized tourist role: the case of Israeli student ex backpapers. Journal of Travel Research. Vol. 46, 2007, pp. 217-226.

REISINGER, Y.; F. MAVONDO. "Travel Anxiety and Intention to Travel internationally: implication of Travel Risk perception". Journal of Travel Research, 43, 2005, pp. 212-245.

ROBSON, L. Risk Management for meetings and Events. Annals of Tourism Research, 35 (3), 2005, pp. 840-842.

SARTRE J. P. El Existencialismo es un humanismo. Buenos Aires: Ediciones del 80, 1997.

STEINER, C. Political instability, Transnational Tourist Companies and Destination Recovery in the Middle East after 9/11. Tourism and Hospitality Planning \& Development. Vol. 4 (3), 2007, pp. 169-190. 
TARLOW, P. (2011). Tourism Disaster Management in a age of Terrorism. Int. Journal of Tourism Anthropology. Special issue on Narrives of Risk, security \& Disasters issues in Tourism and Hosp. KORSTANJE, M. (editor). Vol. 1 (3-4), pp. 254-272.

TIERNEY, K. Sociology's Unique Contributions to the Study of Risk. Disaster Research Center, Preliminary Paper, 204, 1994.

ZINN, J. O. Biography, Risk and Uncertainty - is there common ground for biographical Research and Risk Research. FQS, Forum, Qualitative Social Research. Vol. 11 (1). Paper 15, 2010.

Recebido em: 29-03-2012.

Aprovado em: 29-04-2012. 